\title{
Response of adult rats to deficiencies of different essential amino acids
}

\author{
BY A. K. SAID,* D. M. HEGSTED AND K. C. HAYES \\ Department of Nutrition, Harvard School of Public Health, \\ Boston, Massachusetts, USA
}

(Received I3 March I973-Accepted I9 7 uly 1973)

\begin{abstract}
I. Adult rats were fed on diets free of either lysine, methionine, threonine or protein. The threonine- and protein-deficient animals lost weight at approximately the same rate, about $100 \mathrm{~g}$ in 14 weeks, at which time several were moribund. In contrast, lysine-deficient animals lost only about $30 \mathrm{~g}$ in 14 weeks and had lost only $46 \mathrm{~g}$ after 22 weeks, when they were killed. Methioninedeficient animals showed an intermediate response. Losses in weight of several tissues - kidney, heart and two muscles - were related to, but not necessarily proportional to, the loss of bodyweight. Liver weights relative to body-weights were large in lysine- and threonine-deficient animals and smallest in methionine-deficient animals.

2. Adult rats were fed on diets containing zero, a moderate amount (about twice the estimated minimal requirement) or an excess (about four times the estimated requirement) of lysine or threonine in all combinations $(3 \times 3$ design). Analysis of variance of the body-weights, tissue weights and tissue nitrogen contents indicated, in general, a significant effect of each amino acid, as expected, but also, in most instances, a significant interaction. Plasma concentrations of lysine and threonine were affected by the intakes of the respective amino acids, but plasma lysine concentrations were also affected by the threonine intake.

3. Liver histology also suggested significant interactions between the two amino acids. Animals given no lysine but moderate amounts of threonine developed severely fatty livers; next most severely affected were animals receiving excess of both amino acids. Threonine deficiency, in the presence or absence of lysine, produced moderately fatty livers similar to those seen in protein-deficient animals.

4. Since animals have varying ability to conserve body nitrogen when they are fed on diets limiting in different essential amino acids, measurements of biological value (Bv) and net protein utilization by conventional methods, over a short period of time, over-estimate nutritive value relative to amino acid score and probably over-estimate the true nutritive value of poor-quality proteins, particularly those limiting in lysine. If so, this is a serious error, since it leads to underestimates of the protein requirements if $\mathrm{BV}$ is used. The fact that certain tissues, particularly the liver, do not necessarily lose nitrogen in proportion to total body nitrogen and may show specific pathological effects depending on the limiting amino acid or the proportions of amino acids in the diet also indicates that general measures of nitrogen economy may not be sufficiently discriminating tests of the nutritive value of proteins.
\end{abstract}

It is abundantly clear that the nutritional quality of dietary proteins is dependent on, if not entirely determined by, the essential amino acid content of the protein. The concept of an amino acid score has been strongly supported by the observation that there is a significant correlation between the calculated score (the adequacy of the most limiting amino acid relative to a protein or amino acid mixture assumed to be 'ideal') and observed biological value (BV) or net protein utilization (NPU) (Block \& Mitchell, I946-7; FAO, I957; WHO, I965). This concept thus assumes that the nutritional quality of a protein will be compromised to an equal degree by equivalent degrees of deficiency of any essential amino acid or that protein synthesis will be equally impaired by a lack of any essential amino acid.

\footnotetext{
* Present address: Nutrition Institute, i6 Kasr El-Aini Street, Cairo, Egypt.
} 
This concept seems inherently valid since all amino acids must be present in appropriate amounts if protein synthesis is to occur. It is now clear, however, that traditional measures of protein quality, such as BV or NPU, do not yield values in conformity with these expectations. Animals fed on diets completely lacking in most essential amino acids do not lose weight or body protein at rates similar to those fed on a protein-free diet (Bender, r96ı; Yamashita \& Ashida, 1969; Said \& Hegsted, 1970). Thus, they yield values for BV or NPU considerably in excess of the expected value. Although the biochemical mechanisms involved are not known, there must be adaptive changes which permit the conservation of many essential amino acids when these are in short supply. In our experience, it is only in deficiencies of threonine, isoleucine and total sulphur amino acids that such adaptive mechanisms are minimal (Said \& Hegsted, 1970). Animals fed on such diets lose weight and body tissue at approximately the same rate as animals given no protein at all. On the other hand, adaptation to diets free of lysine is marked, and animals given no lysine lose weight and tissue very slowly. Other amino acids fall in between these extremes.

The results of two experiments which explore these problems are presented in this paper. The first is a simple extension of the previous studies (Said \& Hegsted, 1970) demonstrating that a lack of different essential amino acids does not result in similar losses of body tissue. The second represents an investigation of the response to lysine or threonine deficiency in the presence of a deficiency or modest excess of the other amino acid.

\section{EXPERIMENTAL}

The studies were conducted with young adult female rats (Charles River Breeding Laboratories, Wilmington, Massachusetts) weighing between 200 and $220 \mathrm{~g}$. The purified diets were similar to those used in previous studies which contained either a low level of lactalbumin (Nutritional Biochemical Corp., Cleveland, Ohio) or a mixture of amino acids (Ajinomoto Co., New York) as the source of nitrogen. The amino acid mixture, also previously described (Said \& Hegsted, 1970), was based upon the work of Rao, Metta \& Johnson (1959) except for the lysine content. Each kg of diet provided, unless the amino acid content was specifically modified, the following amounts of the natural L-isomers (g): histidine hydrochloride monohydrate, 0.896 ; isoleucine, $\mathrm{I} \cdot 75^{2} ;$ leucine, $2 \cdot 192$; phenylalanine, $\mathrm{I} \cdot 336$; tyrosine, $0 \cdot 952$; cystine, $\mathrm{I} \cdot 080$; tryptophan, 0.352 ; arginine hydrochloride, $1 \cdot 072$; methionine, 0.500 ; lysine hydrochloride, $2 \cdot 000$; threonine, $\mathrm{I} \cdot 500$; valine, $\mathrm{I} \cdot 200$; glutamic acid, 8.408; glycine, 4.288; ammonium citrate, $6 \cdot 464$. When amino acids were omitted from the diets, they were replaced by an equivalent amount of the non-essential nitrogen mixture so that the diets were isonitrogenous.

On arrival in the laboratory, the animals were individually caged and given a diet containing $24 \mathrm{~g}$ lactalbumin $/ \mathrm{kg}$ for I week. They were then divided into similar groups by weight and offered the various diets ad lib. The first experiment involved five groups of ten rats each. Diets free of either lysine, methionine, threonine or protein were given as well as a diet containing $17.7 \mathrm{~g}$ lactalbumin $(\mathrm{N} \times 6.25)$ per $\mathrm{kg}$. This level of lactalbumin approximates to the amount required to maintain body-weight in such 
animals (Said \& Hegsted, I969). Half the animals were killed after 8 weeks and the remainder after either 14 or 22 weeks, and the liver, right kidney, brain, and the left soleus and plantaris muscles were removed and weighed. A sample of blood was taken for estimation of haemoglobin and packed cell volume.

In the second experiment there were ten groups of five animals each. They received diets containing $\mathrm{I} \cdot 78$ or $3.5^{6} \mathrm{~g}$ lysine $/ \mathrm{kg}$ or $0,2 \cdot 4$ or $4.8 \mathrm{~g}$ threonine/ $\mathrm{kg}$ diet in all possible combinations $(3 \times 3$ factorial design). The tenth group was given a proteinfree diet. The intermediate levels of lysine and threonine $\left(\mathrm{I} \cdot 7^{8}\right.$ and $2 \cdot 40 \mathrm{~g}$ lysine and threonine, respectively) represent approximately twice the estimated requirement for these amino acids (Said $\&$ Hegsted, 1970). Thus these levels provided a complete deficiency, a presumed adequate level, and a modest excess of each. In this experiment all animals were injected intraperitoneally with $\left[\mathrm{U}-{ }^{14} \mathrm{C}\right]$ valine (New England Nuclear, Cambridge, Massachusetts) at the start of the experiment and the valine content of the amino acid mixture was doubled. The expectation was that a relatively high dietary level of valine would minimize the re-utilization of the labelled valine released by protein catabolism and the counts remaining in the tissues would provide an estimate of the rates of synthesis and degradation. Samples of all homogenized tissues were counted for radioactivity at the end of the experiment. The diets had no appreciable effect upon the radioactivity remaining in the various tissues. It is now known (unpublished results) that feeding with valine does not reduce re-utilization of the labelled valine sufficiently to provide a satisfactory estimate of tissue-protein turnover. Hence, the results are not presented.

Food consumption was measured and the animals were killed after 6 weeks on the experiment. The above-mentioned organs were weighed and either the entire organ or a weighed sample was homogenized in saline. Total nitrogen was determined by the micro-Kjeldahl method. Blocks of liver were also removed and fixed in 10\% buffered formalin before being embedded in paraffin and cut for preparation of haematoxylin and eosin microscopic sections. Representative frozen sections were also cut with a cryostat and stained with Oil-Red-O for study of distribution of liver fat. Plasma free amino acids were estimated with an amino acid analyser (Technicon Corp., Tarrytown, New York) on a plasma sample deproteinized with sulphosalicylic acid (Efron, 1965). Organ weights and analyses were also obtained from a group of animals killed at the start of the study to provide normal values.

\section{RESULTS}

Changes in the body-weights of the animals during the first experiment are presented graphically in Fig. I. Five animals from each group were killed after 8 weeks, when the threonine- and protein-deficient groups had lost approximately $30 \%$ of their original body-weight. The remaining animals from these two groups were killed after I4 weeks, when they had lost approximately $50 \%$ of their original weight and some appeared to be moribund. At this time the animals receiving the lysine-free diet had lost only $14 \%$ of their original weight and the animals receiving the methionine-free diet had lost $28 \%$ of their original weight. These animals were killed after the $22 n d$ 


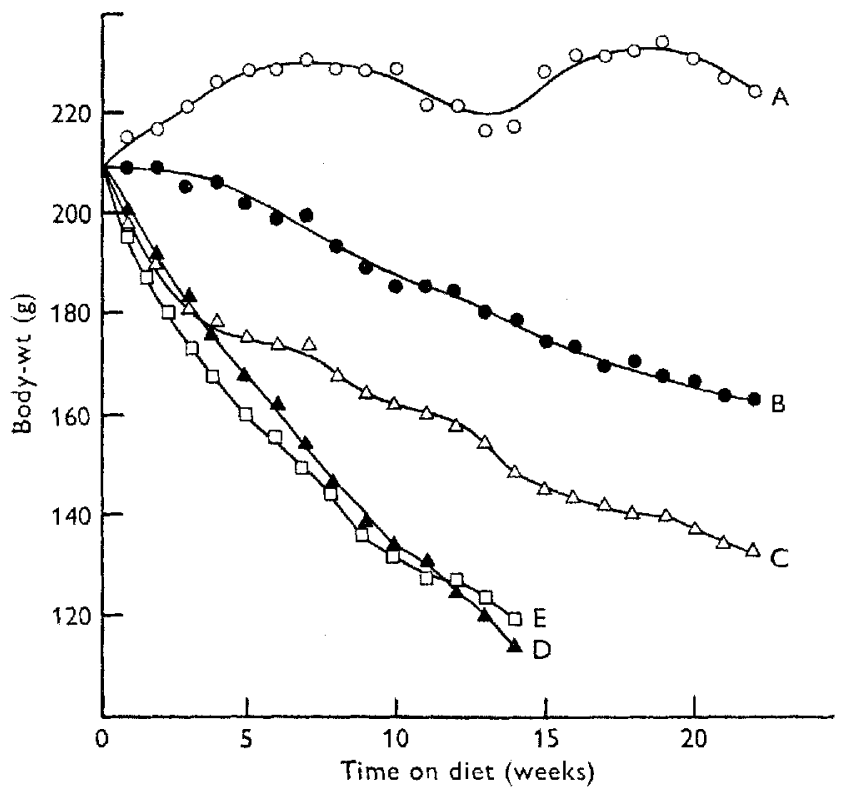

Fig. 1. Expt I. Average body-weights of rats fed on various diets. A, lactalbumin (1 $7 \cdot 7 \mathrm{~g} / \mathrm{kg})$;

$B$, lysine-free diet; $C$, methionine-free diet; $D$, threonine-free diet; $E$, protein-free diet.

week of the experiment, when they had lost $21 \%$ and $36 \%$, respectively, of their original weight. Rats fed on the lactalbumin diet had maintained their body-weight or gained approximately $5 \%$ of it by 22 weeks.

Organ weights and the results of the analyses for haemoglobin and packed cell volume, obtained when the animals were killed, are shown in Table $x$. As is well known, the weight of the brain is not affected, or only slightly affected, by protein deficiency. Other organ weights were substantially decreased by either amino acid or protein deficiency and, although not necessarily proportional to weight loss, they were generally smaller in animals that had experienced the greatest loss in weight. The liver weight appeared to indicate more specific effects. Expressed as a percentage of final bodyweight, the liver weights of the methionine-deficient animals were small, 3.2 and $3.5 \%$ of body-weight, whereas those of the lysine- and threonine-deficient animals were increased compared with those of either the protein-free rats or the rats given the maintenance level of lactalbumin. Histological examination of a limited number of liver sections revealed considerable fat accumulation in those rats given the proteinfree, lysine-free or the lactalbumin diet. Much less fat accumulated in the livers of animals fed on the methionine-free or threonine-free diets.

Moderate to severe anaemia developed in all groups, but was most rapid in those animals with rapid weight loss, specifically the protein-free and threonine-free groups. There were large differences in the response of individual animals within certain groups. For example, in the methionine-free group killed after 22 weeks, the haemoglobin concentration ranged from 44 to $144 \mathrm{~g} / 1$.

Changes in body-weight and terminal organ weights of the animals in Expt 2, killed 
Vol. $3^{\text {I }}$

Deficiencies of essential amino acids

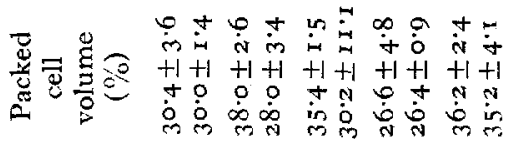

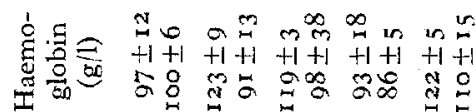

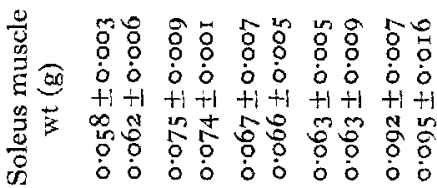

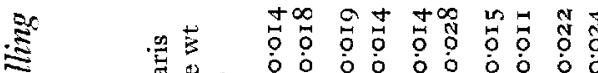

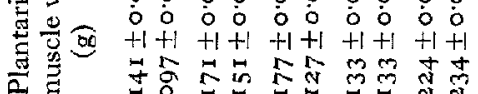

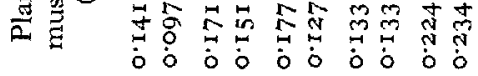

.

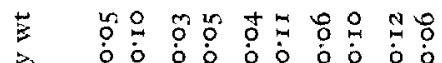

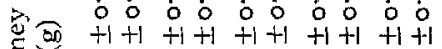

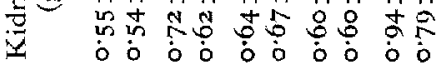

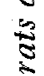

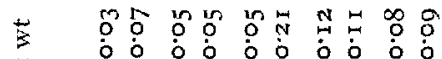

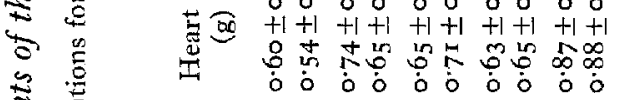

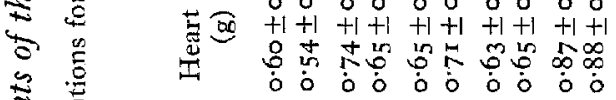

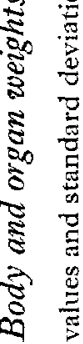

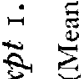

\{

amano nom

is

象

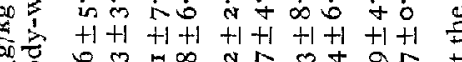

$\overrightarrow{3}$

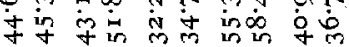

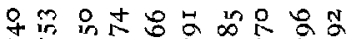

i $\dot{0}: \dot{0} \dot{0} \dot{0} \dot{0} \dot{0}$

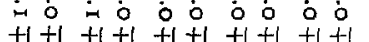

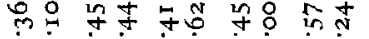

$\dot{0}$ in $\dot{\infty} \dot{\infty}$ in

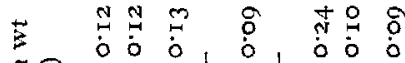

. $30+1+1+1 \mid+11+1+1+1$

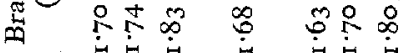

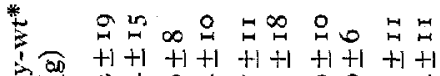

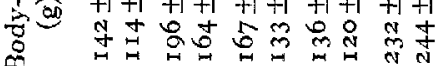

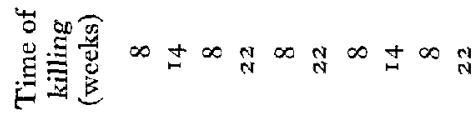

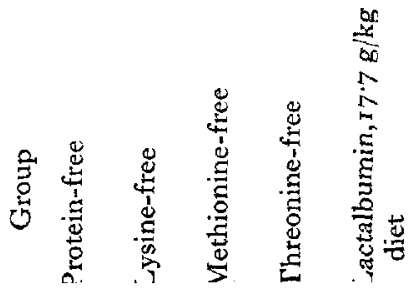




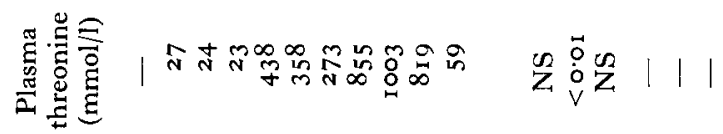

.

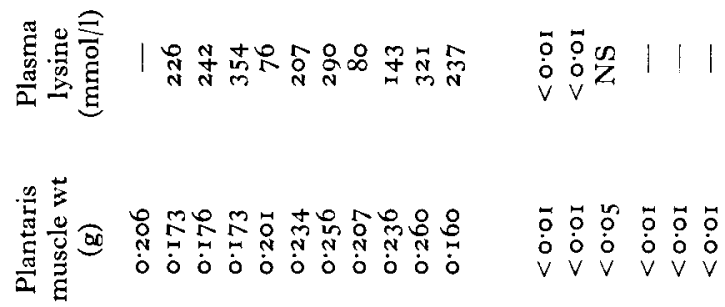

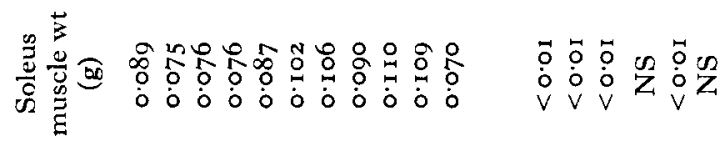

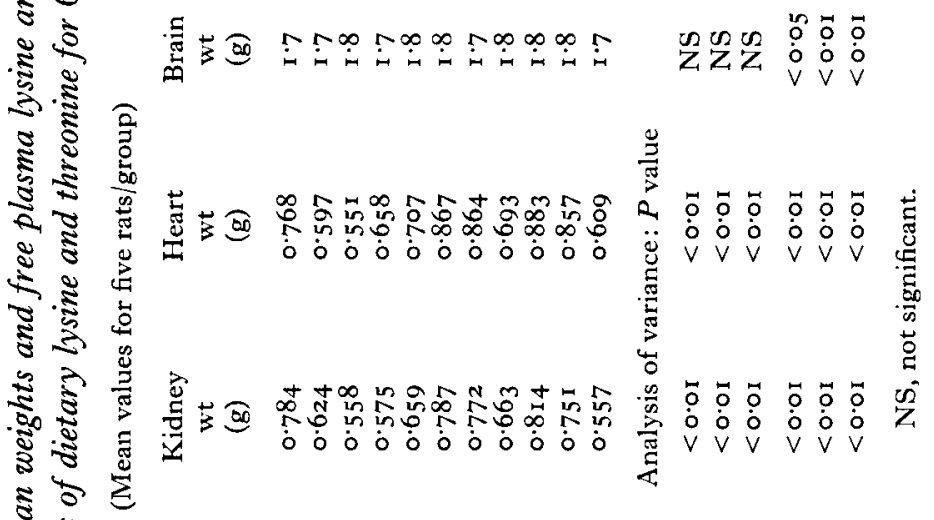

sิ

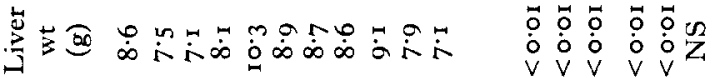

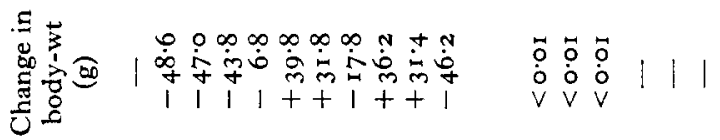

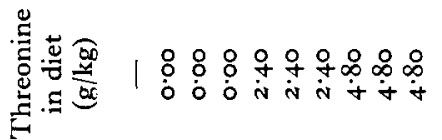



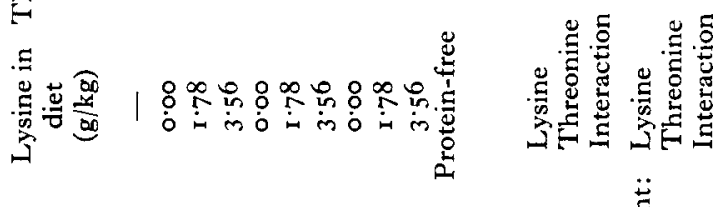

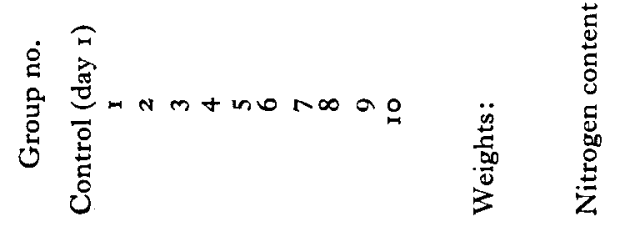


after 6 weeks, are shown in Table 2. As expected, threonine deficiency produced a greater weight loss than lysine deficiency and resembled total protein deficiency in terms of growth and organ weights. Analysis of variance was applied to the results for the nine groups which received the various levels of lysine and threonine to evaluate the effects of each amino acid and to test for interaction between amino acids upon body-weight change, total organ weight, and total organ nitrogen content. A brief summary of these statistical analyses is shown at the bottom of Table 2. With the exception of those for the brain, the results are relatively uniform, indicating a significant effect of each amino acid, as well as significance for the interaction term. The latter indicates that the total effects of these diets are not entirely explained by a summation of the individual effects of each amino acid alone. Values for the nitrogen content of the organs are not presented, but it will be observed from the analysis of variance that, in general, the effects on nitrogen content were similar to those shown for total organ weight.

Because the histological results for the liver were remarkably different between dietary groups, the observations are summarized in Table 3 along with associated values for liver weights, body-weights and food intake. Body-weight losses and histological pictures of the livers from all rats that received the threonine-free diets (groups I-3) were similar. Most hepatocytes from the periportal area to the mid-zone of the lobule were swollen and the dark nucleus stood out from the pale cytoplasm lacking in organelles. A moderate number of cells was distended with fat in single, large droplets. Hepatocytes in rats receiving the modest excess of lysine among these three groups (group 3) were most swollen and contained the most fat. Livers from group 3 were also slightly larger than those from groups $\mathrm{I}$ and 2 , but had a similar protein content.

In contrast, lysine deficiency in the presence of adequate threonine (group 4) resulted in little loss of weight, but produced severely fatty livers. Hepatocytes were extremely distended by lipid droplets, the fat having coalesced into large globules which displaced most of the cytoplasm in the cells throughout the lobule, but especially in the periportal region. Although the livers were enlarged, relatively and absolutely, the total nitrogen content was similar to those of groups $\mathrm{I}-3$. The amount of protein in the liver was markedly depressed. It is of interest that the hepatocytes in the livers of rats from group 7 , which were also lysine-deficient but which received excess threonine, were essentially normal in appearance. A few cells contained a small amount of fat as finely dispersed droplets. The liver nitrogen content was similar to that of the protein-free group and of the threonine-deficient groups, resulting in the second lowest percentage of protein in the liver. A failure to consume an adequate intake of food might be expected to reduce the fat content of the liver, but the food intake of this group was similar to that of group 4 (Table 3 ).

The livers from group 5 which received presumably adequate levels of both lysine and threonine were, as expected, essentially normal, although swollen hepatocytes containing fat droplets were noted in the periportal area of two of these rats. The addition of either excess lysine (group 6) or excess threonine (group 8) to the diet also produced a relatively normal histological picture. However, when an excess of 


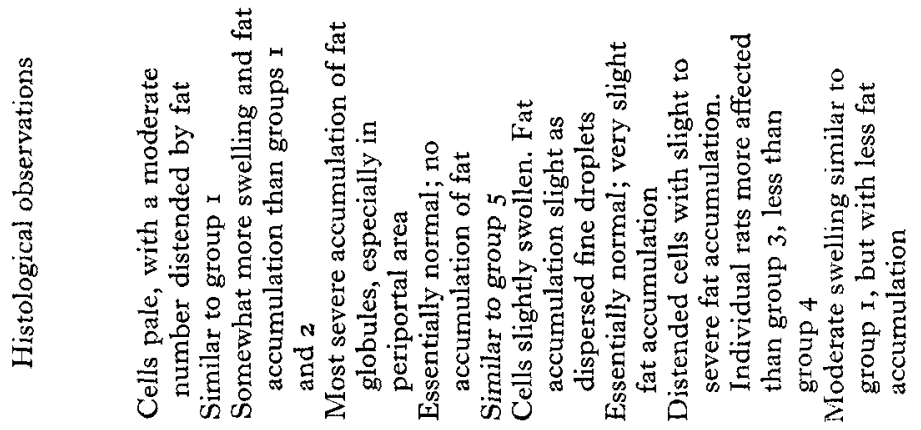

논 离产

i

芷

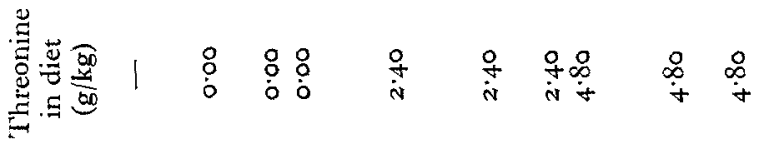

$\stackrel{2}{\stackrel{2}{0}}$

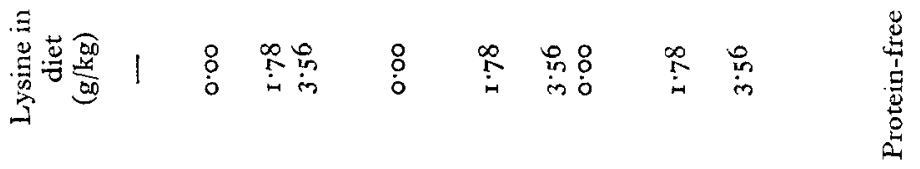

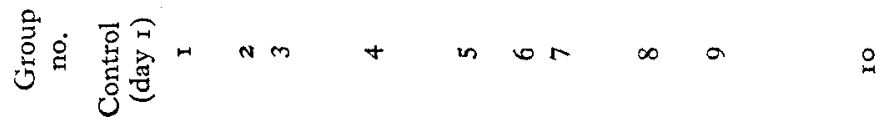


both lysine and threonine was given (group 9) the fatty liver produced in two rats was almost as severe as that produced with no lysine but adequate threonine (group 4). The other livers from group 9 had a mild to moderate amount of lipid. The livers from this group were smallest as a percentage of body-weight and contained the highest percentage of protein of those of any group examined, including the control animals killed on the Ist day of the experiment. The livers of the animals which received the protein-free diet (group ro) were similar to those in groups 1,2 and 3 receiving no threonine, although the livers of the protein-free rats appeared to contain more fat. The total nitrogen content of these livers was the lowest of any group and the percentage of protein was also relatively low.

Free plasma lysine and threonine contents are also shown in Table 2. As expected, the plasma concentrations generally reflect the level in the diet. However, the concentrations in rats which received no threonine were similar to those in animals that had received no protein, and the lysine concentration in these same rats was relatively normal, even when no lysine was included in the diet (group I). Plasma lysine concentrations were low only when lysine was the sole limiting amino acid (groups 4 and 7 ). On the other hand, threonine concentrations responded to threonine administration even though the diet contained no lysine (compare group I with groups 4 and 7 ). In spite of these apparent interactions, the analysis of variance shows no interaction between amino acids upon the plasma concentrations of lysine or threonine. Threonine, however, had a statistically significant effect upon the plasma lysine concentration $(P<O .0 I)$ but lysine had no effect upon the threonine concentration. Since the variance within groups was relatively large, only gross effects would be expected to achieve statistical significance with this number of animals.

\section{DISCUSSION}

The use of amino acid scores as an estimate of protein quality carries the tacit assumption that equivalent degrees of deficiency of any essential amino acid will impair protein utilization to a similar degree. A score of zero (absolute deficiency of any essential amino acid) is assumed to prevent protein utilization and to be the nutritional equivalent of a protein-free diet. It is apparent that a deficiency of threonine approximately fulfils these expectations but deficiencies of most other essential amino acids do not (Bender, 196r; Said \& Hegsted, I970). Lysine deficiency appears to be the most aberrant of all the essential amino acids.

Since prevention of coprophagy does not modify the response to threonine and lysine deficiency (Chang \& Hegsted, 1972), and since there is no reason to suspect that essential amino acids can be synthesized in the body (Steele, 1952), the most likely explanation of these findings is that they represent an adaptive response to amino acid deficiencies. The animal body has varying degrees of ability to conserve the various essential amino acids when they are in short supply, presumably by modifying the rates of catabolism.

The conventional measures of protein quality, such as BV and NPU, compare nitrogen retention on nitrogen-free diets and on those containing the test protein over an 
arbitrarily selected period of time. Since animals given a lysine-free diet, for example, do not lose body nitrogen at the same rate as animals given the threonine-free diet, the BV or NPU of the lysine-free diet will be much higher than the amino acid score. It can scarcely be argued, however, that a lysine-free diet is more adequate nutritionally than a threonine-free diet.

Since most proteins are limiting in either lysine or methionine, both of which can be conserved to a substantial degree, it is clear why NPU and BV over-estimate the nutritional quality of low-quality proteins compared with the amino acid score. This phenomenon is not limited to rats. Inspection of the dose-response curves of human subjects given various dietary levels of essential amino acids suggest marked differences in the degree of negative nitrogen balance obtained with low intakes of essential amino acids (Hegsted, 1963). Inoue, Fujita, Kishi \& Niiyama (1972) have convincingly demonstrated the same phenomenon in adult men by comparing nitrogen balance at various levels of intake of egg protein and wheat gluten. At very low levels of intake (when lysine is no longer limiting in wheat gluten because of lysine conservation), the BV of egg protein and wheat gluten were similar. The dose-response curves for these proteins in man were similar to those seen in rats given varying dietary levels of lactalbumin and wheat gluten (Said \& Hegsted, 1969).

The significance of this adaptive response in practical terms is not very clear. It does not mean that lysine is necessarily less 'essential' than threonine. Comparison of the losses of body-weight in Fig. $\mathrm{I}$ shows that the threonine- and protein-free groups lost about $40 \mathrm{~g}$ of body-weight in 4 weeks, whereas it required approximately 8 weeks for the methionine-deficient and 20 weeks for the lysine-deficient animals to lose the same amount. The difference is in the time required to reach equivalent degrees of deficiency. Nevertheless, the ability to adapt should provide protection against acute deficiencies and may well allow reasonably adequate performance at dietary levels somewhat below estimated requirements. The ability to conserve lysine and other amino acids to a varying degree would partly explain differences in requirements for growth and maintenance, and indicate that the nutritive value of proteins may be quite different for adult and growing animals.

We conclude that measurements of BV and NPU by conventional methods, over a short period of time, over-estimate the true nutritional quality of most poor-quality dietary proteins. This is a more serious error in practical terms than an underestimation of the nutritive value, since it results in an underestimation of the protein requirements. For example, if the true nutritive value of wheat gluten is only $0^{\circ} 15^{-0} \cdot 20$, compared with that of egg protein or lactalbumin (Hegsted \& Chang, 1965), instead of the usually quoted value of $0.40(\mathrm{FAO}, 1957$; WHO, 1965), the estimated requirement of wheat gluten should be at least doubled. Dietary recommendations that err on the low side are more dangerous than those that err on the high side.

The results also point to other defects in classical methods of measuring protein quality and protein requirements. In Expt 2 the lysine-deficient animals maintained their body-weight and the protein content of most tissues compared with the threoninedeficient or protein-deficient animals, but the livers of the lysine-deficient animals were extremely fatty and contained no more protein than those of the rats exposed to 
threonine or protein deficiency. Many factors have been implicated in the development of fatty livers, and the low protein content of the livers of the lysine-deficient animals might have been due in part to the accumulation of fat in the liver. Nevertheless, it is clear that gross measures of nitrogen economy, such as nitrogen balance, provide no clues to effects that different amino acid deficiencies may have upon specific tissues. More discriminating tests are clearly needed.

The results also indicate that the 'most limiting amino acid' does not appear to provide a full description of the influence of the diet. Statistical analyses of the organ weights and organ nitrogen contents usually indicated some significant interaction between the effects of lysine and threonine levels. The meaning of this is not clear and should not be over-emphasized. However, both the biochemical and histological observations point to interactions of biological significance and to substantial differences in the way individual animals react to the same diet.

This work was supported in part by grants-in-aid from the National Institutes of Health (AM-09520 and K6-AMr 8455) and the Fund for Research and Teaching, Department of Nutrition, Harvard School of Public Health.

\section{REFERENCES}

Bender, A. E. (196r). Publs natn. Res. Coun., Wash. no. 843, p. 407.

Block, R. J. \& Mitchell, H. H. (1946-7). Nutr. Abstr. Rev. 16, 249.

Chang, Y.-O. \& Hegsted, D. M. (1972). Proc. Soc. exp. Biol. Med. 139, 522.

Efron, M. L. (1965). In Automation in Analytical Chemistry p. 637 [L. T. Skeggs, Jr, editor]. New York: Mediad Inc.

FAO (1957). F. A. O. nutr. Stud. no. 16.

Hegsted, D. M. (1963). Fedn Proc. Fedn Am. Socs exp. Biol. 22, 1424.

Hegsted, D. M. \& Chang, Y.-O. (1965). F. Nutr. 87, 1.

Inoue, G., Fujita, K., Kishi, K. \& Niiyama, Y. (1972). Int. Congr. Nutr. Ix. Mexico City. (In the Press.)

Rao, P. B. R., Metta, V. C. \& Johnson, B. C. (1959). F. Nutr. 69, 387.

Said, A. K. \& Hegsted, D. M. (1969). F. Nutr. 99, 474.

Said, A. K. \& Hegsted, D. M. (1970). F. Nutr. I00, 1363.

Steele, R. (1952). F. biol. Chem. 198, 237.

WHO (1965). Tech. Rep. Ser. Wld Hlth Org. no. 3or

Yamashita, K. \& Ashida, K. (1969). F. Nutr. 99, 267. 